\title{
Transmesocolic Laparoscopic Left Pyeloplasty: Technical Appraisal and Early Results
}

\author{
Avijit Kumar*, Kaliyaperumal Muruganandham, Dorairajan LN, Ramathiran Manikandan and Santosh Kumar \\ 1Department of Urology, JIPMER, India
}

Submission: November 06, 2017; Published: November 21, 2017

*Corresponding author: Avijit Kumar, Department of Urology, India, Tel: +91-9918222900; Email: avijit16@gmail.com

\begin{abstract}
Laparoscopic pyeloplasty has been considered the standard of care since its introduction by Schuessler in 1993 for ureteropelvic junction obstruction. In this era or surgery where focus is on minimally invasive and minimally morbid procedure, transmesocolic approach for management of left sided ureteropelvic junction obstruction proves itself as standard treatment whenever feasible. Avoiding colon mobilization not only reduces the operative time but also enables early recovery and discharge. We would try to discuss our experience for the same and report excellent postoperative outcomes achieved.
\end{abstract}

\section{Introduction}

Ureteropelvic Junction Obstruction (UPJO) has classically been treated through the standard open approach with outstanding results. Since Anderson-Hynes (AH) reported the first dismembered pyeloplasty, a great number of authors have published excellent results, with overall success rates of $90 \%$ to $100 \%$ [1]. Schuessler et al. [2] first performed a laparoscopic pyeloplasty in 1993. Since then the laparoscopic technique has developed and has been shown to be safe and effective [3]. Today, laparoscopic pyeloplasty has become the preferred treatment for UPJO in centres with advanced laparoscopic expertise and is defined as a valid treatment option. The laparoscopic approach can be transperitoneal or retroperitoneal. Both approaches reproduce the open technique with similar outcomes and minimal morbidity $[4,5]$. When a transperitoneal approach is chosen, the access to the ureteropelvic junction on the right side is easy and usually performed through a small peritoneal incision. Conversely, on the left side the standard technique requires the mobilization of the descending colon. To avoid this surgical step, a direct transmesocolic approach to the left ureteropelvic junction may be considered [6].

We present our experience with dismembered left-sided pyeloplasty using a transmesocolic technique through the mesocolic window as a way to reduce operative time and facilitate repair by avoiding colon displacement.

\section{Material and Methods}

Between September 2010 and September 2012, a total of 10 transmesocolic laparoscopic pyeloplasties were done in our institute. Records of all the patients were reviewed and data pertaining to patient's demographics, clinical presentation, biochemical and radiological investigations as well as findings of renal scan preoperatively and postoperative follow up details were noted. Also details relating to operative time, estimated blood loss, intraoperative findings, duration of hospitalization, intraoperative or postoperative complications if any were also noted. Among the 10 patients two (20\%) were females and eight $(80 \%)$ were males. The mean patients age was 18.3 years (range 13 to 31 years). The mean differential function of kidneys is $37.3 \%$ (range 23 to $51 \%$ ) and all the patient had hydronephrotic kidneys with evidence of pelvicalyceal tracer accumulation and delayed excretion suggestive of UPJO on diuretic renogram. All the patients had complaints of left sided flank pain of and on and the mean duration of symptoms ranged from 4 months to 36 months.

\section{Surgical Technique}

After induction of general anaesthesia and administration of antibiotic prophylaxis, a urethral catheter and a nasogastric tube are inserted. The patient is then placed in a $45^{\circ}$ lateral decubitus, secured to the operative table, prepped and draped. The pneumoperitoneum was induced using an open technique and the intrabdominal pressure at $12-13 \mathrm{mmHg}$ was maintained during the procedure. Three ports were placed (one $10 \mathrm{~mm}$ umbilical port and two $5 \mathrm{~mm}$ ports). After placing the umbilical $10 \mathrm{~mm}$ port a $10 \mathrm{~mm}$ laparoscope with $30^{\circ}$ was introduced in the peritoneal cavity and the other two ports were placed under direct vision, assessment of the bulging dilated pelvis through the mesocolic window was done (Figure 1). This way the left mesentero-colic space which was limited medially by the 
inferior mesenteric vein and laterally by the medial margin of the descending colon, was used as the operative field. A $5 \mathrm{~cm}$ incision was then made longitudinally, lateral to the inferior mesenteric and gonadal veins, in between the medial and left colonic artery, just over the dilated bulging left renal pelvis using a hook cautery. This area is free of vessels and the incision frequently enables a direct visualization of the pelvis and the ureteropelvic junction. To help in dissection the colon was retracted up to the lateral abdominal wall with the help of stay sutures (Figure 2). After opening the mesenteric window dissection of the dilated pelvis was done to expose the ureteropelvic junction and the upper ureter and assessment regarding the presence of a crossing vessel was done. When present the anastomosis was transposed

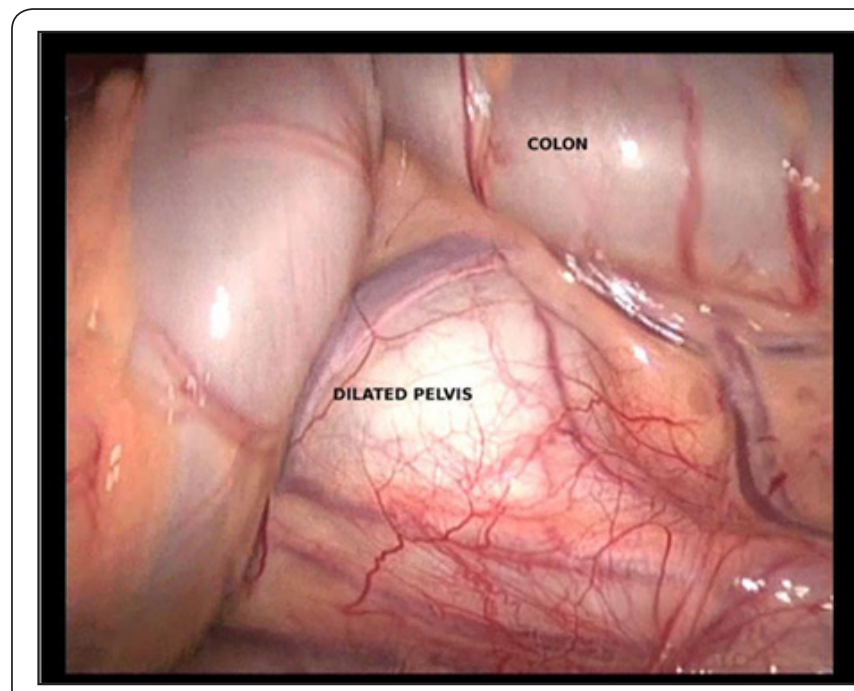

Figure 1: Assessment of the renal pelvis through the mesocolic window.

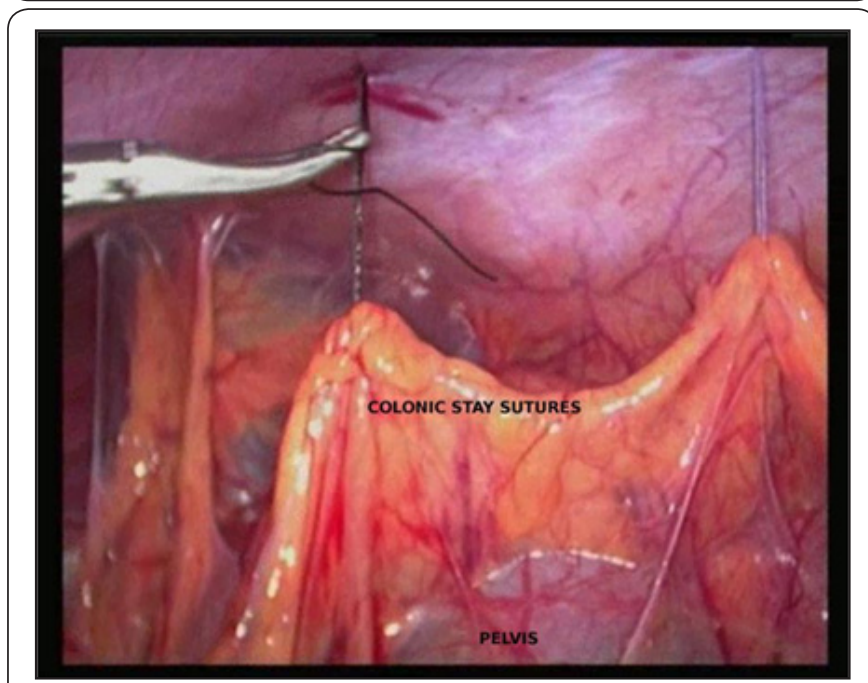

Figure 2 : Stay suture on the colon.

After completion of anastomosis the operative field was checked for hemostasis and the mesocolic window was then anterior or posterior to the crossing vessel. After dissecting the ureteropelvic junction and the upper ureter care was taken not to rip much of the periureteral tissue and then the ureteropelvic junction was incised, the ureter spatulated and dismemberment done (Figure 3). Any redundant pelvis present was also excised. The reconstruction was done using the Anderson-Hynes technique. Anastomosis was done as a "three stitch technique". Posterior layer was sutured first using absorbable suture (Polyglactin 3-0), after that antegrade stenting using a $5 \mathrm{Fr} / 22 \mathrm{~cm}$ Double J stent was done (Figure 4), followed by the closure of the anterior layer and closure of the pelvis (Figure 5). Suturing was done in a running fashion.

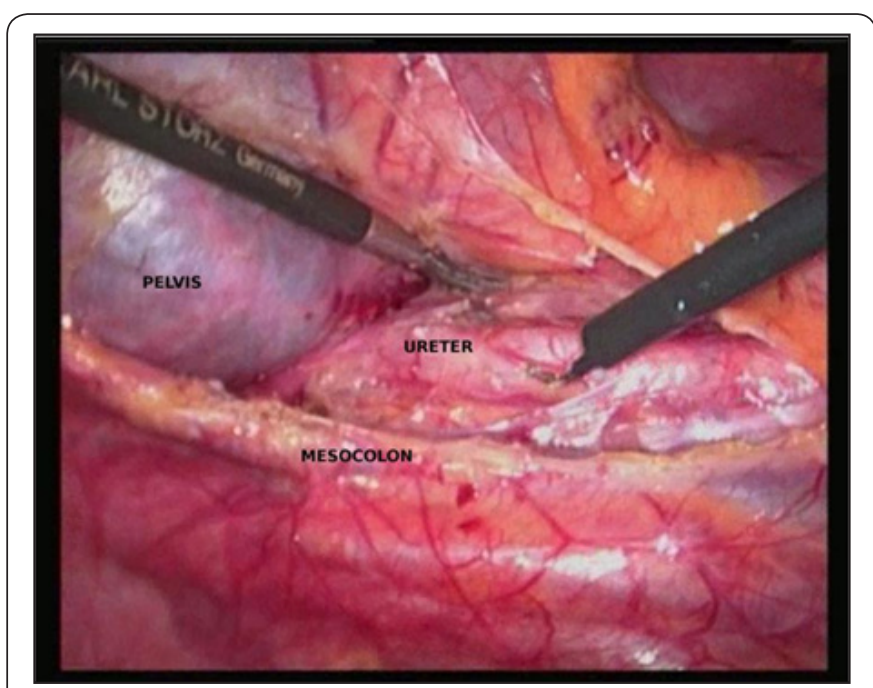

Figure 3 : Dissection of renal pelvis and ureter.

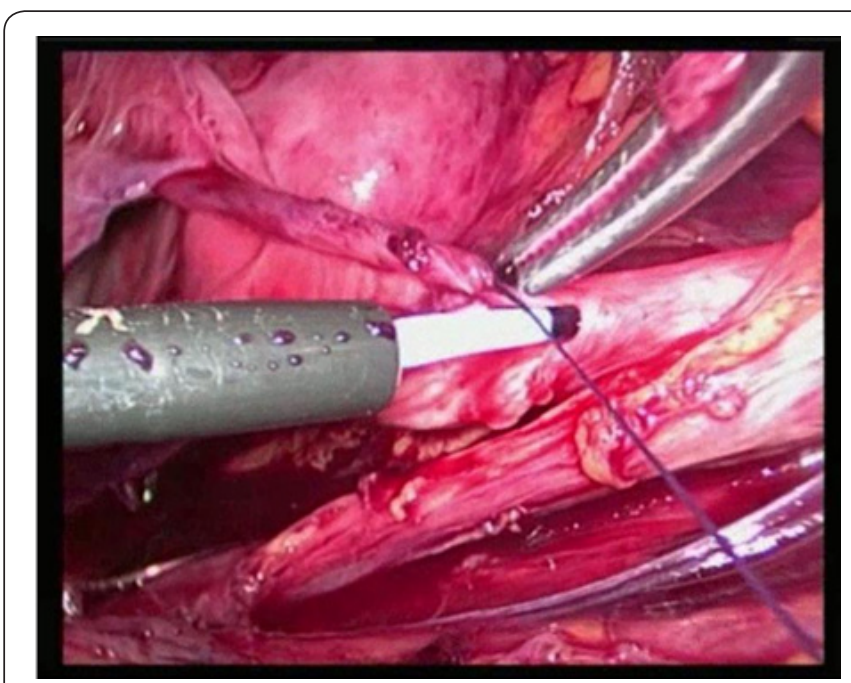

Figure 4: Antegrade stenting.

closed using interrupted sutures with Polyglactin 3-0. A suction drain was placed. Ports closed. 


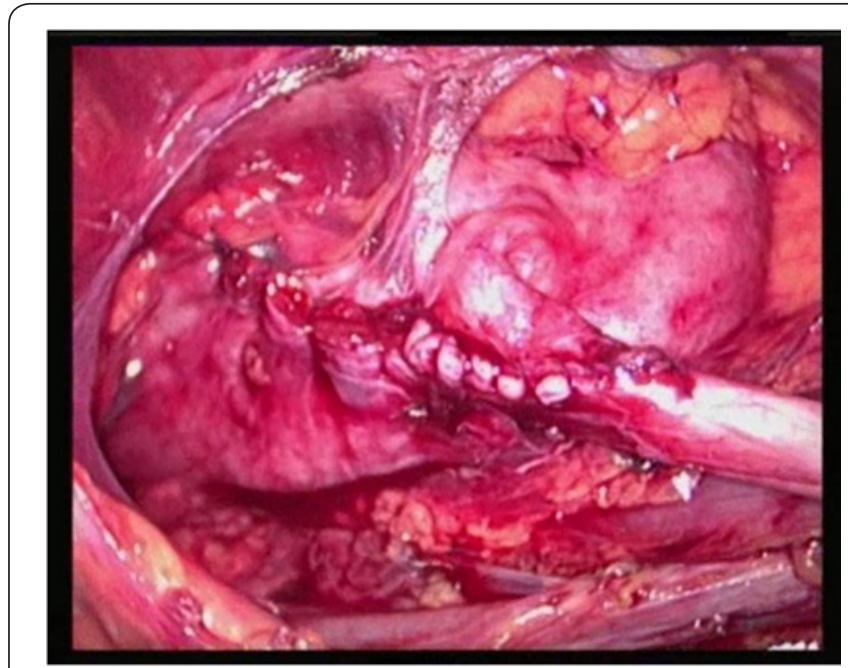

Figure 5 : Final appearance after closure of all the layers.

Patient was then monitored for vitals, urine and drain output in the intensive care unit. If all parameters were within normal range perurethral catheter was removed after 24 hours and if no increase in drain output then the drain was removed after another 24 hours. Patient was allowed orally by mouth on the evening of the surgery and discharged on the third or fourth postoperative day. Patient was then called on follow up after seven days for stitch removal. The double J stent was removed after six weeks and the follow up renal scan was done at three months from the date of surgery.

\section{Results}

The procedure was completed successfully in all patients and there was no need for conversion to open. The mean operative time was 2.5 hours (range 1.5 to 4 hours). Blood loss was minimal. Two (20\%) patient has an anteriorly crossing vessel which was transposed posteriorly after dismemberment. Post operative period uneventful. All patients tolerated oral feeds at evening of day 1 . There was minimal need of postoperative analgesia for all the patients. One patient had high drain output for 3 days and perurethral catheter was kept for 4 days. In all other patients PUC was removed on Day 2 and drain on Day 3. The average hospital stay was 3.5 days postoperatively. At the mean follow up of 28 weeks ( 4 weeks to 52 months) all patients $(100 \%)$ were asymptomatic and the post operative nuclear renal scan in nine patients showed preserved function with decreased hydronephrosis and improved drainage on the ipsilateral side. One patient is yet to complete 3 months post surgery and renal scan is thus awaited.

\section{Discussion}

At present, dismembered Anderson-Hynes pyeloplasty is the gold standard for the treatment of primary UPJO [1,5]. To duplicate the steps of open pyeloplasty with a minimal invasive approach, in the 1990s Schuessler et al. [2] first described the technique of laparoscopic pyeloplasty. Laparoscopy has shown the advantage of being able to address both intrinsic and extrinsic causes of obstruction in a manner similar to the open approach. Pyeloplasty can be carried out via a transperitoneal or a retroperitoneal approach the choice of approach is a matter of surgeon's skill and expertise.

When a transperitoneal approach is chosen for a rightside laparoscopic pyeloplasty, the access to the ureteropelvic junction is simple. In fact, the surgeon has only to lift up the liver to identify the renal pelvis. Thus, the pyeloplasty can be performed through a small incision in the posterior peritoneum that will be sutured at the end of the procedure [8]. Conversely, with a standard approach on the left side, mobilization of the descending colon is mandatory to identify the underlying renal fascia and to access the ureteropelvic junction [3]. However, the descending colon can reduce the width of the operative field, especially in obese patients or when the colon is distended. In these cases, the introduction a fourth trocar is often required to improve the exposure.

To avoid the mobilization of the descending colon and all the inherent problems associated with bowel manipulation, a direct transperitoneal access to the left ureteropelvic junction was proposed [9]. This technique was first described in paediatric urology by Cisek et al. [6] and recently applied in adult urology by Romero et al. [10] and Castillo et al. [11], who reported series of 18 and 11 patients, respectively. This approach provides a good operative field to easily make the anastomosis and has several advantages compared with the standard technique. As there is minimal bowel mobilization there is theoretical chance of early bowel recovery and less bowel complications. We could see this in all of our patients who had excellent postoperative recovery with early return of bowel activity.

Fortunately all the patients we operated upon were non obese and thus we were not confronted with the problem of fatty mesocolic window which would have caused difficulty during dissection. Porpiglia et al. [12] did transmesocolic pyeloplasty in 18 patients and concluded that outcome was not statistically significant among patients with BMI more than or less than 25 $\mathrm{kg} / \mathrm{m}^{2}[12]$.

The risk of compromising the colonic vascularisation with the mesenteric incision seems to be virtually absent because the main mesenteric vessels are spared. In fact, the incision is made between the medial and the left colonic artery and only a few minor branches are sometimes sectioned. It is of utmost importance to be familiar with the anatomy of mesentero-colic window to achieve adequate exposure without compromising the colonic blood supply. This area is a relatively avascular area of entry and this knowledge would help is achieving the adequate success.

Based on these considerations, the direct access through the mesentero-colic space should be considered when a left laparoscopic pyeloplasty is indicated, especially in slim patients 
and in patients with a large renal pelvis. Nevertheless, to better define the role of this approach in the treatment of UPJO, further information is needed from larger series with a longer followup. Moreover, studies comparing the outcomes of this technique with those of the standard approach are recommended.

\section{Conclusion}

Transmesocolic approach to left sided UPJO is straightforward approach resulting in shorter operative time, and earlier bowel recovery with excellent postoperative outcome. Case selection is of paramount importance as obese patient may pose a surgical challenge for a beginner. With adequate knowledge of the mesentero-colic window and skilled dissection optimal result and excellent postoperative outcome is guaranteed. Thus this approach should be considered for all patients with primary left UPJO who are eligible for a laparoscopic pyeloplasty and especially for slim patients or patients with a large renal pelvis.

\section{References}

1. Munver R, Sosa E, Del Pizzo J (2004) Laparoscopic pyeloplasty: History, evolution, and future. J Endourol 18(8): 748-755.

2. Schuessler WW, Grune MT, Preminger GM (1993) Laparoscopic dismembered pyeloplasty. J Urol 150: 1795-1799.

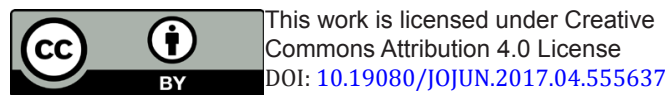

3. Turk IA, Davis JW, Winkelmann B, Deger S, Richter F, et al. (2002) Laparoscopic dismemebered pyeloplasty-the method of choice in the presence of an enlarged renal pelvis and crossing vessels. Eur Urol 42(3): 268-275.

4. Bachmann A, Ruszat R, Forster T, et al. (2006) Retropertioneoscopic pyeloplasty for ureteropelvic junction obstruction (UPJO): solving the technical difficulties. Eur Urol 49(2): 265-272.

5. Jarrett TW, Chan DY, Charambura TC, Fugita O, Kavoussi LR (2002) Laparoscopic pyeloplasty: the first 100 cases. J Urol 167(3): 12531256.

6. Cisek A, Chen K, Chang K, Chang LS (2004) Pediatric laparoscopic pyeloplasty. J Endourol Suppl 18: A219.

7. Kaouk JH, Gill IS (2005) Laparoscopic reconstructive urology. J Urol 170(4 Pt 1): 1070-1078.

8. Romero FR, Wagner AA, Trapp C, et al. (2006) Transmesenteric laparoscopic pyeloplasty. J Urol 176(6 Pt 1): 2526-2529.

9. Castillo OA, Vitagliano G, Alvarez JM, Pinto I, Toblli J (2007) Transmesocolic pyeloplasty: experience of a single center. J Endourol 21(4): 415-418.

10. Porpiglia F, Billia M, Volpe A, Morra I, Scarpa RM (2008) Transperitoneal left laparoscopic pyeloplasty with transmesocolic access to the ureteropelvic junction: techniques description and results with a minimal follow-up of 1 year. BJU Int 101(8): 1024-1028.

\section{Your next submission with Juniper Publishers will reach you the below assets}

- Quality Editorial service

- Swift Peer Review

- Reprints availability

- E-prints Service

- Manuscript Podcast for convenient understanding

- Global attainment for your research

- Manuscript accessibility in different formats

( Pdf, E-pub, Full Text, Audio)

- Unceasing customer service

Track the below URL for one-step submission https://juniperpublishers.com/online-submission.php 